\title{
Identification, Pathogenicity, and Spore Trapping of Colletotrichum karstii Associated with Twig and Shoot Dieback in California
}

\author{
Joey S. Mayorquin, ${ }^{1}$ Mohamed T. Nouri, ${ }^{2}$ Beth B. Peacock, ${ }^{1}$ Florent P. Trouillas, ${ }^{2}$ Greg W. Douhan, ${ }^{3}$ \\ Craig Kallsen, ${ }^{4}$ and Akif Eskalen ${ }^{5, \dagger}$ \\ ${ }^{1}$ Department of Microbiology and Plant Pathology, University of California, Riverside, CA 92521; ${ }^{2}$ Department of Plant Pathol- \\ ogy, University of California, Davis, Kearney Agricultural Research and Extension Center, Parlier, CA 93648; ${ }^{3}$ University of \\ California Cooperative Extension, Tulare, CA 93274; ${ }^{4}$ University of California Cooperative Extension, Bakersfield, CA \\ 93307; and ${ }^{5}$ Department of Plant Pathology, University of California, Davis, CA 95616
}

\begin{abstract}
Colletotrichum Corda, 1831 species are well-documented pathogens of citrus that are associated with leaf and fruit anthracnose diseases. However, their role in twig and shoot dieback diseases of citrus has recently become more prominent. Recent surveys of orchards in the Central Valley of California have revealed C. gloeosporioides and a previously undocumented species, $C$. karstii, to be associated with twig and shoot dieback. Pathogenicity tests using clementine (cv. 4B) indicated that both

C. karstii and C. gloeosporioides are capable of producing lesions following inoculation of citrus stems. Pathogenicity tests also revealed $C$. karstii to be the most aggressive fungal species producing the longest lesions after 15 months. The majority of spores trapped during this study were trapped during or closely following a precipitation event with the majority of spores being trapped from January through May. These findings confirm C. karstii as a new pathogen of citrus in California.
\end{abstract}

The 2017-2018 U.S. citrus crop was valued at \$3.28 billion, with California's citrus production accounting for $59 \%$ of the overall U.S. production. Much of California's bearing acreage is devoted to orange production; however, other citrus varieties of tangerine, mandarin, lemon, and grapefruit are grown throughout the state (USDA-NASS 2018). As the California citrus industry is important, the identification and management of new disease threats is crucial.

Colletotrichum constitutes a large genus of ascomycetous fungi that are known for having diverse ecological roles ranging from endophytes to plant pathogens. Colletotrichum includes some important fungal pathogens of numerous plant hosts including native and agricultural plant species occurring in tropical and subtropical regions (Cannon et al. 2012; Dean et al. 2012; Hyde et al. 2009). Colletotrichum is well known for causing various anthracnose diseases, with general anthracnose symptoms including necrotic lesions on various plant parts including stems, leaves, flowers, and fruits (Agrios 2005). Although Colletotrichum is primarily described as causing anthracnose diseases, other diseases such as rots caused by Colletotrichum spp. have been documented (Cannon et al. 2012; Lenne 2002).

The taxonomy of Colletotrichum spans well over a century of history and has gone through many revisions, especially since recent advances in DNA technologies. Currently, over 100 species of Colletotrichum have been described and a thorough review of the history of Colletotrichum classification can be found in Cannon et al. (2012). Recent phylogenetic studies of three well established Colletotrichum species (C. gloeosporioides, $C$. acutatum, and $C$. boninense) revealed that these species represent species complexes and collectively account for at least 71 phylogenetic species (Damm et al. 2012; Weir et al. 2012). The large species diversity within the

${ }^{\dagger}$ Corresponding author: A. Eskalen; aeskalen@ucdavis.edu

Funding: Financial support for this project was provided by the Citrus Research Board (Project \# 5400-152).

The author(s) declare no conflict of interest.

Accepted for publication 5 January 2019.

(C) 2019 The American Phytopathological Society
Colletotrichum genus highlights the importance of DNA phylogenies to identify species accurately.

Historically, two species of Colletotrichum, C. gloeosporioides (Penz.) Penz. \& Sacc. and C. acutatum J.H. Simmonds, have been associated with anthracnose diseases of citrus (Timmer et al. 2000). These anthracnose diseases, which include postharvest anthracnose, postbloom fruit drop (PFD), and key lime anthracnose (KLA), are of great economic importance (Damm et al. 2012; Timmer et al. 2000). Additionally, twig dieback (known as withertip) is known to occur in citrus (Klotz 1961) and shoot blight can occur in advanced stages of KLA (Peres et al. 2008). Recent evidence suggests that additional species of Colletotrichum previously unknown from citrus are causing diseases of citrus globally, particularly from the $C$. boninense species complex. C. karstii You L. Yang, Zuo Y. Liu, K.D. Hyde \& L. Cai (C. boninense species complex) has been increasingly reported from anthracnose symptoms of citrus worldwide and is often found to occur in association with other Colletotrichum spp., particularly C. gloeosporioides, which generally predominates within citrus hosts (Guarnaccia et al. 2017; Huang et al. 2013; Peng et al. 2012; Ramos et al. 2016). C. karstii has been increasingly reported also from anthracnose diseases of other crops including avocado, mango, and persimmon (Ismail et al. 2015; Lima et al. 2013; Silva-Rojas and Ávila-Quezada 2011; Wang et al. 2016) and is considered the most common and widely distributed species of the $C$. boninense species complex (Damm et al. 2012). Although C. karstii has been reported from citrus in China, Italy, and Portugal (Aiello et al. 2015; Guarnaccia et al. 2017; Huang et al. 2013; Peng et al. 2012; Ramos et al. 2016), in the United States, C. karstii has only been reported from Leucospermum (Crous et al. 2013) and Phalaenopsis spp. (Jadrane et al. 2012). In North America, $C$. karstii has been reported in Mexico from two additional hosts, Annona cherimola (Damm et al. 2012) and Musa sp. (Velázquez-del Valle et al. 2016).

Recently, unusual disease symptoms associated with Colletotrichum spp. were observed frequently in various Citrus orchards in the San Joaquin Valley of California (Eskalen, personal observation). Symptoms included leaf chlorosis, twig and shoot dieback, crown thinning, wood cankers in branches, and in some cases, death of young plants. Isolation from diseased tissues yielded typical Colletotrichum species based on colony morphology, but slight differences also suggested that more than one species might be present. To date, C. gloeosporioides has been the only species associated with anthracnose diseases of citrus in California. Therefore, the objectives of this 
study were to: (i) identify Colletotrichum species associated with twig and shoot dieback as well as branch canker of Citrus spp. in California; (ii) assess the pathogenicity of Colletotrichum spp. in twigs of Citrus spp.; and (iii) to determine when and under what environmental conditions spores of Colletotrichum spp. were dispersed within CA citrus orchards based on spore trapping.

\section{Materials and Methods}

Field survey and fungal isolations. Field surveys were conducted in 13 commercial citrus orchards throughout Madera Co. (one orchard), Fresno Co. (three orchards), Tulare Co. (four orchards), and Kern Co. (five orchards) from 2014 to 2016. The main citrus varieties sampled from Kern and Tulare counties were 'Clemenules' clementine, 'Fukumoto' and 'Washington' navel, Valencia orange, and 'Fisher' navels for Madera County, with an average orchard age of 11 years. Orchards were sampled during both the spring and fall of that same year for orchards in Madera, Tulare, and Kern counties. Approximately 16 trees were sampled from each orchard during each sampling period. Samples included portions of blighted twigs and shoots, and cankered branches. The samples were transported in an ice chest to the laboratory and stored at $5^{\circ} \mathrm{C}$ until processed for isolations.

Prior to isolation, twig and shoot samples were rinsed with distilled water to remove surface debris and disinfested by spraying with $95 \%$ ethanol and briefly flaming. To isolate from the margin of necrotic tissues, bark was removed with a flame sterilized paring knife and small pieces of tissue containing both necrotic and healthy tissue were plated onto potato dextrose agar (PDA) (Difco Laboratories) amended with $0.01 \%$ tetracycline hydrochloride (Fisher Scientific). Plates were incubated at room temperature $\left(\sim 23\right.$ to $\left.25^{\circ} \mathrm{C}\right)$ in the dark for approximately 5 to 7 days. Single-spore cultures were obtained from fungal colonies with developed acervuli by using a sterile inoculation loop to scoop spore masses from acervuli and streak them onto water agar plates. After $24 \mathrm{~h}$, isolated germinating conidia were picked off with a sterile inoculating needle and transferred to new PDA plates with the aid of a stereomicroscope. Each culture derived from a single conidium was used to determine morphological and molecular characterizations and is stored in a culture collection maintained by the Eskalen lab at the University of California, Davis, CA.

Morphological characterization. Fungi were initially identified to the genus level based on cultural and microscopic examination (colony color, colony growth pattern, growth rate, and conidia shape). Of those resembling Colletotrichum spp., several representative isolates from each orchard were further studied using published descriptions (Damm et al. 2012). To examine spore morphology, isolates were grown on synthetic nutrient-poor agar medium (SNA), oatmeal agar (OA), and/or PDA to induce conidial production and incubated under continuous fluorescent light for about 2 weeks at an average temperature of 23 to $25^{\circ} \mathrm{C}$ as described by Damm et al. (2012). Conidial masses were scooped with a toothpick and mounted in a drop of lactoglycerol on a microscope slide. The lengths and widths of approximately 30 conidia per isolate were measured using SPOT Imaging software (Diagnostic Instruments Inc., MI). Appressoria were also measured from cultures using a modified slide culture technique (Harris 1986) with plugs of SNA as the culture medium. Slide cultures were incubated under the conditions described above and mounted in lactoglycerol for microscopic examination. The length and width of at least 15 appressoria were measured for each isolate examined. The mean, standard deviation, minimum, mode, and maximum conidial lengths and widths, in addition to the mean and standard deviation of appressorium lengths and widths, were calculated for each isolate using Microsoft Excel (Microsoft Corporation, Redmond, WA).

DNA isolation, amplification, and phylogenetic analysis. Genomic DNA for each isolate was extracted using a slightly modified method of Cenis (1992). Oligonucleotide primers ITS4 and ITS5 (White et al. 1990) were used to amplify the ITS1-5.8S-ITS2 regions of the rDNA locus, primers $\mathrm{T} 1$ and Bt2b (White et al. 1990) were used to amplify a partial region of the nuclear beta-tubulin gene (TUB2), and primers GDF1 and GDR1 (Guerber et al. 2003) were used to amplify a 200-bp intron of the glyceraldehyde-3-phosphate dehydrogenase gene (GAPDH). Polymerase chain reaction (PCR) was carried out essentially as described by Damm et al. (2012). Reaction mixtures consisted of $1 \times$ reaction buffer, $0.2 \mathrm{mM}$ dNTPs, $0.2 \mu \mathrm{M}$ forward and reverse primers, $2.5 \mathrm{U}$ of standard Taq polymerase (New England Biolabs, MA), and template DNA ranging from 50 to $100 \mathrm{ng} / \mu \mathrm{l}$. For ITS, cycling conditions were as follows: an initial preheat at $95^{\circ} \mathrm{C}$ for $2 \mathrm{~min}$, followed by 40 cycles of denaturation at $95^{\circ} \mathrm{C}$ for $15 \mathrm{~s}$, annealing at $55^{\circ} \mathrm{C}$ for $30 \mathrm{~s}$, and extension at $72^{\circ} \mathrm{C}$ for $2 \mathrm{~min}$, followed by a final extension at $72^{\circ} \mathrm{C}$ for $5 \mathrm{~min}$. For TUB2 and GAPDH, cycling conditions were as described by Damm et al. (2012). PCR products were purified using ExoSAP-IT (Affymetrix, CA) following the manufacturer's instructions and sequenced at the Institute for Integrative Genome Biology of the University of California, Riverside, using both forward and reverse primers for each locus.

Sequences were edited using Sequencher 4.6 software (Gene Codes Corp., MI) and alignments done using ClustalX (Thompson et al. 1997). Phylogenetic analysis was performed with MEGA6 (Tamura et al. 2013) and sequences in the present study (Table 1) were compared with known sequences in GenBank (Table 1). Separate analyses were run for each gene region dataset in addition to a combined dataset of all three genes after visually examining individual gene tree topology for congruence among the three genes. Maximum parsimony analysis was performed for each dataset using the SubtreePruning-Regrafting (SPR) search method with gaps and missing data treated as a complete deletion. Bootstrap values were obtained from 1,000 bootstrap replications and tree length, consistency index $(\mathrm{CI})$, retention index (RI), rescaled consistency index (RC), and homoplasmy index (HI) were recorded. Additionally, neighbor-joining (NJ) and maximum likelihood (ML) analyses were performed for the combined dataset using the maximum composite likelihood model with uniform rates $(\mathrm{NJ})$ and the Kimura 2-parameter model with gamma distribution and nearest-neighborinterchange heuristic method (ML), for both ML and NJ analyses. Gaps and missing data were treated as complete deletions and bootstrap values were obtained from 1,000 bootstrap replications.

Pathogenicity tests. Two pathogenicity tests were conducted using 2-year-old potted clementine ' $4 \mathrm{~B}$ ' trees grafted to Carrizo rootstock and maintained in a greenhouse at the University of California, Riverside. In the first pathogenicity test, four trees were stem inoculated by making wounds approximately 6 inches above the soil line using a 5-mm diameter cork-borer to remove bark and expose the cambium. Mycelial plugs were taken from the edge of a 1-week-old colony of $C$. gloeosporioides and $C$. karstii (Table 1) and were placed into the wounds; noninfested PDA plugs were used for controls. Wounds were covered with petroleum jelly and wrapped with Parafilm. This experiment was conducted twice. Plants were maintained in the greenhouse for 10 days before being destructively sampled to measure internal vascular necrosis (lesions). Small pieces of tissue from the margin of lesions were plated onto PDA amended with $0.01 \%$ tetracycline hydrochloride. Emerging fungal colonies were recorded and identified by sequencing the ITS region as previously described.

For the second pathogenicity test, four 2-year-old potted clementine '4B' trees grafted to Carrizo rootstock and maintained in a greenhouse at the University of California, Riverside were inoculated using a sterile scalpel to remove bark and expose an approximately 5 -mm strip of cambium 6 inches from the soil line in four plants. A $20-\mu$ l drop of a conidial suspension in sterile water $\left(1 \times 10^{6}\right.$ spores $/ \mathrm{ml}$ ) obtained from fungal cultures grown on PDA for about 1 week at an average temperature of 23 to $25^{\circ} \mathrm{C}$ was pipetted onto the wound and a sterile 18-gauge needle was inserted through the droplet and into the xylem to facilitate suspension uptake; sterile water was applied to control plants. Resulting wounds were covered with petroleum jelly and wrapped with Parafilm. This experiment was conducted twice. Inoculated plants were maintained in the greenhouse for approximately 15 months (December 2015 to March 2017) before being destructively sampled to measure internal vascular necrosis. Small pieces of tissue from the margin of lesions were plated 
onto PDA amended with $0.01 \%$ tetracycline hydrochloride to fulfill Koch's postulates. Emerging fungal colonies were recorded and identified by sequencing their ITS regions.

Spore trapping. Spore trapping was done using sticky glass microscope slide traps as described by Eskalen and Gubler (2001). Traps were placed in four citrus orchards (two orchards each in Kern and Tulare counties) previously surveyed for approximately two years (2017 to 2018). Ten traps were deployed in each orchard for a total of 40 traps. One spore trap was randomly placed on a branch of a tree and traps were collected and replaced every 2 weeks and shipped to the laboratory for further processing. Once received, slide traps were rinsed with sterile deionized water in $50 \mathrm{ml}$ falcon tubes and two $100-\mu l$ aliquots of this wash were spread plated onto PDA amended with $0.01 \%$ tetracycline hydrochloride and incubated in a dark cabinet for 5 days. Fungal colonies resembling Colletotrichum were identified by gross colony morphology as described previously. Colony forming units (CFU) were assumed to be derived from a single spore and were counted and recorded. Weather data (mean temperature, total monthly rainfall, and mean relative humidity) were collected from the nearest weather stations from each orchard to determine possible correlation between the release of fungal spores and weather conditions.

Statistical analyses. Lesion lengths for pathogenicity tests were analyzed using JMP Pro 12 (SAS Institute). Levene's test was used to determine the homogeneity of variance between independent trials; no heterogeneity was detected and data from independent trials were combined. Lesion length data were $\log _{10}$ transformed to normalize data; however, data from the initial pathogenicity test could not be normalized after transformation, and thus lesion lengths were analyzed by a Kruskal-Wallis test with confidence level $\alpha=0.05$. Mean lesion lengths of fungal inoculated plants compared with control plants were evaluated using the steel with control method with confidence level $\alpha=0.05$. For the second pathogenicity test, mean lesion lengths were compared using a one-way analysis of variance. Mean lesion lengths of fungal inoculated plants compared with control plants were evaluated using Dunnett's method with

Table 1. Representative isolates of Colletotrichum spp. collected from citrus shoot cankers in California and fungal species obtained from GenBank

\begin{tabular}{|c|c|c|c|c|c|c|c|}
\hline \multirow[b]{2}{*}{ Species $^{\mathrm{a}}$} & \multirow[b]{2}{*}{ Isolate $^{b}$} & \multirow[b]{2}{*}{ Location } & \multirow[b]{2}{*}{ Host } & \multirow[b]{2}{*}{ Cultivar } & \multicolumn{3}{|c|}{ GenBank accession $^{c}$} \\
\hline & & & & & ITS & GAPDH & TUB2 \\
\hline Colletotrichum karstii & KARE523 & Fresno & Citrus reticulata & $\ldots$ & KY076519 & KY304041 & KY086302 \\
\hline C. karstii & KARE524 & Fresno & C. reticulata & $\ldots$ & KY076520 & KY304042 & KY086303 \\
\hline C. karstii & KARE525 & Fresno & C. reticulata & $\ldots$ & KY076521 & KY304043 & KY086304 \\
\hline C. karstii & KARE526 & Fresno & C. reticulata & $\ldots$ & KY076522 & KY304044 & KY086305 \\
\hline C. karstii & KARE530 & Fresno & C. reticulata & $\ldots$ & KY076523 & KY304045 & KY086306 \\
\hline C. karstii & KARE531 & Fresno & C. reticulata & $\ldots$ & KY076524 & KY304046 & KY086307 \\
\hline C. karstii & KARE534 & Fresno & C. reticulata & $\ldots$ & KY076525 & KY304047 & KY086308 \\
\hline C. karstii & KARE536 & Fresno & C. reticulata & $\ldots$ & KY076526 & KY304048 & KY086309 \\
\hline C. karstii & KARE545 & Fresno & C. reticulata & $\ldots$ & KY076527 & KY304049 & KY086310 \\
\hline C. karstii & UCR1717 & Tulare & C. sinensis & Cara Cara & MK101014 & $\ldots$ & $\ldots$ \\
\hline C. karstii & UCR1761 & Tulare & C. sinensis & Cara Cara & KY076528 & KY304050 & KY086311 \\
\hline C. karstii & UCR $1763^{d}$ & Tulare & C. sinensis & Cara Cara & KY076529 & KY304051 & KY086312 \\
\hline C. karstii & UCR2263 & Madera & C. sinensis & Fisher & KY076530 & KY304052 & KY086313 \\
\hline C. karstii & UCR2264 & Madera & C. sinensis & Fisher & KY076531 & $\ldots$ & $\ldots$ \\
\hline C. karstii & UCR2275 & Madera & C. sinensis & Fisher & KY076532 & $\ldots$ & $\ldots$ \\
\hline C. karstii & UCR2456 & Tulare & Spore trap & $\ldots$ & KY076533 & $\ldots$ & $\ldots$ \\
\hline C. karstii & UCR2457 & Tulare & Spore trap & $\ldots$ & KY076534 & $\ldots$ & $\ldots$ \\
\hline C. karstii & UCR2473 & Tulare & Spore trap & $\ldots$ & KY076535 & $\ldots$ & $\ldots$ \\
\hline C. karstii & UCR2475 & Tulare & Spore trap & $\ldots$ & KY076536 & $\ldots$ & $\ldots$ \\
\hline C. karstii & UCR2510 & Tulare & Spore trap & $\ldots$ & KY076537 & $\ldots$ & $\ldots$ \\
\hline C. karstii & UCR2545 & Tulare & Spore trap & $\ldots$ & KY076538 & $\ldots$ & $\ldots$ \\
\hline C. karstii & UCR2553 & Tulare & C. reticulata & Clemenules & KY076539 & $\ldots$ & $\ldots$ \\
\hline C. karstii & UCR2556 & Tulare & C. reticulata & Clemenules & KY076540 & $\ldots$ & $\ldots$ \\
\hline C. karstii & UCR2563 & Tulare & C. reticulata & Clemenules & KY076541 & KY304053 & KY086314 \\
\hline C. karstii & UCR2571 & Tulare & C. reticulata & $4 \mathrm{~B}$ & KY076542 & KY304054 & KY086315 \\
\hline C. karstii & UCR2572 & Tulare & C. reticulata & 4B & KY076543 & $\ldots$ & $\ldots$ \\
\hline C. karstii & UCR2576 & Tulare & C. reticulata & $4 B$ & KY076544 & KY304055 & KY086316 \\
\hline C. karstii & UCR3550 & Kern & C. reticulata & $\ldots$ & MK101015 & $\ldots$ & $\ldots$ \\
\hline C. karstii & UCR3552d & Kern & C. reticulata & Clemenules & KY076545 & KY304056 & $\ldots$ \\
\hline C. karstii & UCR $3553^{\mathrm{d}, \mathrm{e}}$ & Kern & C. reticulata & Clemenules & KY076546 & KY304057 & KY086317 \\
\hline C. karstii & UCR3554 & Kern & C. reticulata & Clemenules & KY076547 & KY304058 & KY086318 \\
\hline C. karstii & UCR3561 & Kern & C. reticulata & Clemenules & KY076548 & KY304059 & KY086319 \\
\hline C. gloeosporioides & KARE31 & Solano & C. sinensis & $\ldots$ & KY076549 & KY304060 & KY086320 \\
\hline C. gloeosporioides & KARE36 & Solano & C. sinensis & $\ldots$ & KY076550 & $\ldots$ & $\ldots$ \\
\hline C. gloeosporioides & KARE37 & Solano & C. sinensis & $\ldots$ & KY076551 & KY304061 & KY086321 \\
\hline C. gloeosporioides & KARE527 & Fresno & C. reticulata & $\ldots$ & KY076552 & KY304062 & KY086322 \\
\hline C. gloeosporioides & KARE528 & Fresno & C. reticulata & $\ldots$ & KY076553 & KY304063 & KY086323 \\
\hline \multirow{2}{*}{ C. gloeosporioides } & KARE532 & Fresno & C. reticulata & $\ldots$ & KY076554 & KY304064 & KY086324 \\
\hline & & & & & & \multicolumn{2}{|c|}{ (Continued on next page) } \\
\hline
\end{tabular}

\footnotetext{
a Species in bold denote GenBank accessions.

b Isolate codes correspond to Kearney Agricultural Research and Extension Center (KARE), University of California, Riverside (UCR), and Centraalbureau voor Schimmelcultures (CBS).

${ }^{\mathrm{c}}$ ITS = internal transcribed spacer; GAPDH = glyceraldehyde-3-phosphate dehydrogenase; TUB2 = beta-tubulin.

${ }^{\mathrm{d}}$ Isolates selected for morphological characterization (Table 2).

${ }^{\mathrm{e}}$ Isolates used in pathogenicity tests.

${ }^{\mathrm{f}}$ Denotes type/ex-type material.
} 
confidence level $\alpha=0.05$. Figures were made using SigmaPlot (version 11; Systat Software Inc.)

\section{Results}

Field survey and fungal isolation. The most common symptoms observed included twig and shoot dieback, gummosis, and in some cases branch dieback and wood cankers (Fig. 1). All symptoms were found throughout all 13 orchards surveyed. However, the single orchard surveyed from Madera Co. had a low incidence of twig and shoot dieback compared with the other 12 orchards surveyed. There were no obvious correlations between symptoms and all rootstock/ scion combinations sampled in this study: 'Fisher' navel on trifoliate, '4B' clementine on Carrizo, 'Clemenules' clementine on Carrizo, 'Fukumoto' navel on carrizo, and 'Washington' navel on troyer, and Valencia on trifoliate.

A total of 284 symptomatic samples were collected from the 13 orchards. Of the 284 samples, 98 yielded species of Colletotrichum; 6 , 57,100 , and $18 \%$ from Madera, Tulare, Fresno, and Kern counties, respectively. C. karstii was recovered from 3, 31, 50, and $12 \%$ of samples collected from Madera, Tulare, Fresno, and Kern counties, respectively, whereas $C$. gloeosporioides was recovered from 3, 22,70 , and $10 \%$ of samples collected from Madera, Tulare, Fresno, and Kern counties, respectively.

Other fungi isolated from symptomatic tissues were identified using colony characteristics and sequencing the ITS regions of representative isolates as described previously and included Alternaria spp., Penicillium spp., Fusarium sp., Quambalaria spp., Botryosphaeriaceae spp., and Diatrypaceae spp. Botryosphaeriaceae spp. were recovered from 27 of the 284 samples collected and Diatrypaceae spp. were recovered from eight of the 284 samples. Both Botryosphaeriaceae and Diatrypaceae spp., known 'canker' pathogens associated with citrus, were never co-isolated with species of Colletotrichum.

Morphological characterization. Isolates of Colletotrichum from this study could usually be divided into two distinct groups based on colony morphology. However, there were many isolates where the distinction was not obvious, which was the reason molecular tools were used to identify the distinct species. The first group consisted of colonies that were white- to cream-colored, pale orange

Table 1. (Continued from previous page)

\begin{tabular}{|c|c|c|c|c|c|c|c|}
\hline \multirow[b]{2}{*}{ Species $^{\mathbf{a}}$} & \multirow[b]{2}{*}{ Isolate $^{\mathbf{b}}$} & \multirow[b]{2}{*}{ Location } & \multirow[b]{2}{*}{ Host } & \multirow[b]{2}{*}{ Cultivar } & \multicolumn{3}{|c|}{ GenBank accession $^{c}$} \\
\hline & & & & & ITS & GAPDH & TUB2 \\
\hline C. gloeosporioides & KARE533 & Fresno & C. reticulata & $\ldots$ & KY076555 & KY304065 & KY086325 \\
\hline C. gloeosporioides & KARE538 & Fresno & C. reticulata & $\ldots$ & KY076556 & KY304066 & KY086326 \\
\hline C. gloeosporioides & KARE539 & Fresno & C. reticulata & $\ldots$ & KY076557 & KY304067 & KY086327 \\
\hline C. gloeosporioides & KARE541 & Fresno & C. reticulata & $\ldots$ & KY076558 & KY304068 & KY086328 \\
\hline C. gloeosporioides & KARE543 & Fresno & C. reticulata & $\ldots$ & KY076559 & KY304069 & KY086329 \\
\hline C. gloeosporioides & KARE546 & Fresno & C. reticulata & $\ldots$ & KY076560 & KY304070 & KY086330 \\
\hline C. gloeosporioides & KARE548 & Fresno & C. reticulata & $\ldots$ & KY076561 & KY304071 & KY086331 \\
\hline C. gloeosporioides & KARE549 & Fresno & C. reticulata & $\ldots$ & KY076562 & KY304072 & KY086332 \\
\hline C. gloeosporioides & UCR2410 & Fresno & C. sinensis & Fisher & MK101016 & $\ldots$ & $\ldots$ \\
\hline C. gloeosporioides & UCR2411 & Fresno & C. sinensis & Fisher & MK101017 & $\ldots$ & $\ldots$ \\
\hline C. gloeosporioides & UCR2412 & Fresno & C. sinensis & Fisher & MK101018 & $\ldots$ & $\ldots$ \\
\hline C. gloeosporioides & UCR2544 & Tulare & Spore trap & $\ldots$ & KY076563 & $\ldots$ & $\ldots$ \\
\hline C. gloeosporioides & UCR $2552^{\mathrm{d}, \mathrm{e}}$ & Tulare & C. reticulata & Clemenules & KY076564 & KY304073 & KY086333 \\
\hline C. gloeosporioides & UCR2564 & Tulare & C. reticulata & Clemenules & KY076565 & $\ldots$ & $\ldots$ \\
\hline C. gloeosporioides & UCR2569 & Tulare & C. reticulata & Clemenules & KY076566 & KY304074 & KY086334 \\
\hline C. gloeosporioides & UCR2575 & Tulare & C. reticulata & $4 \mathrm{~B}$ & KY076567 & KY304075 & KY086335 \\
\hline C. gloeosporioides & $\mathrm{UCR} 3551^{\mathrm{d}}$ & Kern & C. reticulata & Clemenules & KY076568 & KY304076 & KY086336 \\
\hline Colletotrichum boninense & CBS112115 & Australia & Leucospermum sp. & $\ldots$ & JQ005160 & JQ005247 & JQ005594 \\
\hline C. boninense & CBS123755 f & Japan & Crinum asiaticum var. sinicum & $\ldots$ & JQ005153 & JQ005240 & JQ005588 \\
\hline Colletotrichum sp. & CBS123921 & Japan & Dendrobium kingianum & $\ldots$ & JQ005163 & JQ005250 & JQ005597 \\
\hline C. cymbidiicola & CBS123757 & Japan & Cymbidium sp. & $\ldots$ & JQ005168 & JQ005255 & JQ005602 \\
\hline C. cymbidiicola & CBS128543 & New Zealand & Cymbidium sp. & $\ldots$ & JQ005167 & JQ005254 & JQ005601 \\
\hline C. oncidii & CBS129828f & Germany & Oncidium sp. & $\ldots$ & JQ005169 & JQ005256 & JQ005603 \\
\hline C. oncidii & CBS130242 & Germany & Oncidium sp. & $\ldots$ & JQ005170 & JQ005257 & JQ005604 \\
\hline C. torulosum & CBS102667 & New Zealand & Passiflora edulis & $\ldots$ & JQ005165 & JQ005252 & JQ005599 \\
\hline C. torulosum & CBS128544f & New Zealand & Solanum melongena & $\ldots$ & JQ005164 & JQ005251 & JQ005598 \\
\hline C. brassicicola & CBS101059f & New Zealand & Brassica oleracea var. gemmifera & $\ldots$ & JQ005172 & JQ005259 & JQ005606 \\
\hline C. beeveri & CBS128527 & New Zealand & Brachyglottis repanda & $\ldots$ & JQ005171 & JQ005258 & JQ005605 \\
\hline C. colombiense & CBS129817 & Colombia & P. edulis & $\ldots$ & JQ005173 & JQ005260 & JQ005607 \\
\hline C. colombiense & CBS129818f & Colombia & P. edulis & $\ldots$ & JQ005174 & JQ005261 & JQ005608 \\
\hline C. petchii & CBS118193 & China & Dracaena sanderana & $\ldots$ & JQ005227 & JQ005314 & JQ005661 \\
\hline C. petchii & CBS118774 & China & D. sanderana & $\ldots$ & JQ005225 & JQ005312 & JQ005659 \\
\hline C. annellatum & CBS129826 & Colombia & Hevea brasiliensis & $\ldots$ & JQ005222 & JQ005309 & JQ005656 \\
\hline C. phyllanthi & CBS175.67 & India & Phyllanthus acidus & $\ldots$ & JQ005221 & JQ005308 & JQ005655 \\
\hline C. karstii & CBS106.91 & Brazil & Carica papaya & $\ldots$ & JQ005220 & JQ005307 & JQ005654 \\
\hline C. karstii & CBS110779 & South Africa & Eucalyptus grandis & $\ldots$ & JQ005198 & JQ005285 & JQ005632 \\
\hline C. brasiliense & CBS128501 ${ }^{\mathrm{f}}$ & Brazil & P. edulis & $\ldots$ & JQ005235 & JQ005322 & JQ005669 \\
\hline C. brasiliense & CBS128528 & Brazil & P. edulis & $\ldots$ & JQ005234 & JQ005321 & JQ005668 \\
\hline C. parsonsiae & CBS128525 f & New Zealand & Parsonsia capsularis & $\ldots$ & JQ005233 & JQ005320 & JQ005667 \\
\hline C. hippeastri & CBS125377f & China & Hippeastrum vittatum & $\ldots$ & JQ005230 & JQ005317 & JQ005664 \\
\hline C. hippeastri & CBS125376 & China & H. vittatum & $\ldots$ & JQ005231 & JQ005318 & JQ005665 \\
\hline C. dacrycarpi & CBS130241 ${ }^{\mathrm{f}}$ & New Zealand & Dacrycarpus dacrydioides & $\ldots$ & JQ005236 & JQ005323 & JQ005670 \\
\hline C. constrictum & CBS128503 & New Zealand & S. betaceum & $\ldots$ & JQ005237 & JQ005324 & JQ005671 \\
\hline C. constrictum & CBS128504 ${ }^{\mathrm{f}}$ & New Zealand & Citrus limon & $\ldots$ & JQ005238 & JQ005325 & JQ005672 \\
\hline C. gloeosporioides & CBS112999f & Italy & C. sinensis & $\ldots$ & JX010152 & JX010056 & JX010445 \\
\hline Monilochaetes infuscans & CBS869.96 & Unknown & Unknown & $\ldots$ & JQ005780 & JX546612 & JQ005864 \\
\hline
\end{tabular}


on reverse, and with numerous conidiomata (orange-colored) developing over time throughout the colony. Conidia were hyaline, straight, and cylindrical with rounded ends. These isolates matched closely published descriptions of $C$. karstii (Damm et al. 2012) (Table 2). The second group consisted of isolates forming cream to gray colonies, with dark gray aerial mycelium developing over time, reverse colony color was cream to mottled gray. Conidiomata (orange-colored) were abundant throughout the colony. Conidia from these isolates were hyaline, straight, and cylindrical with rounded ends. These isolates resembled descriptions of C. gloeosporioides (Weir et al. 2012).

Phylogenetic analysis. Individual analysis of the ITS, GAPDH, and TUB2 datasets yielded similar topologies based on all phylogenetic methods used (data not shown). Therefore, only the combined dataset is reported based on maximum parsimony. The combined data set consisted of 1,092 nt, with 225 conserved sites, 851 variable sites, and 290 parsimony-informative sites. Maximum parsimony analysis generated two trees with scores of $\mathrm{CI}=0.68, \mathrm{RI}=0.93$, and $\mathrm{RCI}=0.63$. The combined data set (Fig. 2) revealed that isolates from this study grouped into two well-supported clades. The first major clade ( $91 \%$ bootstrap support) consisted of isolates from this study and other vouchered specimens of $C$. karstii that included reference isolate CBS106.91 of C. karstii. C. phyllanthi and C. annellatum were the most closely related species to $C$. karstii. The second major clade ( $99 \%$ bootstrap support) grouped isolates from this study and the type specimen of C. gloeosporioides (CBS112999). There were only slight nucleotide differences between species of all isolates used in this study within all three loci (Fig. 2).

Pathogenicity tests. In the first pathogenicity test, internal lesions were produced in stems of the inoculated plants and typical acervuli of Colletotrichum were produced near the inoculation site 10 days after inoculation. More than half of the plants inoculated with C. karstii and only one plant inoculated with $C$. gloeosporioides produced acervuli. In the majority of cases, gumming was also observed surrounding the point of inoculation for inoculated plants but not for control plants. There was a significant difference $\left(\chi^{2}=17.627 ; P<\right.$ 0.001 ) in lesion lengths produced between the two fungal treatments (Fig. 3); no internal lesions were observed in control shoots. Lesions produced by both Colletotrichum spp. were brown to chocolatebrown and extended from both ends of the inoculation point. A significant difference in lesion lengths was found between the control plants and plants inoculated with $C$. karstii $(P=0.003)$ and $C$. gloeosporioides $(P=0.015)$ and between fungal species $(P=0.013)$. Fungal recovery of isolates from inoculated stems ranged between 25 to 100\%; no Colletotrichum spp. were recovered from control stems.

In the second pathogenicity test, internal vascular necrosis was observed in plants inoculated with both $C$. karstii and C. gloeosporioides (Fig. 4) 15 months after inoculation. Necrotic regions were brown to chocolate-brown and extended from both ends of the inoculation point. No lesions nor vascular streaking was observed in control plants. Unlike the first pathogenicity test, no fruiting bodies were observed at the point of inoculation. A significant difference $(P<0.001)$ was observed between fungal treatments and there was a significant difference in lesion lengths produced by $C$. karstii $(P<$ $0.001)$ and $C$. gloeosporioides $(P=0.035)$ and the control and between fungal species $(P<0.001)$. Fungal recovery from inoculated shoots ranged from 25 to $100 \%$ and no Colletotrichum spp. were recovered from control plants.

Spore trapping. The majority of fungal spores were trapped during or after precipitation events. In Kern County (Fig. 5A), the majority of spores were trapped during or closely following a precipitation event in March-April 2017 and Feb-March 2018. In Tulare County (Fig. 5B), the majority of spores were trapped during or closely following precipitation events between April-May 2017 and January 2018. Total spore counts between the two orchards trapped in Kern Co. were higher than counts observed in Tulare Co. ( $>60$ spores) during March 2017, April 2017, February 2018, and March 2018. Across all locations, the majority of spores were trapped when average temperatures were between 10 and $25^{\circ} \mathrm{C}$.

\section{Discussion}

This is the first study to report $C$. karstii as a pathogen of citrus causing twig and shoot dieback with or without gumming and occasionally branch dieback and wood canker in the Central Valley of California. Pathogenicity tests on clementine mandarin confirmed that $C$. karstii is a more aggressive pathogen of citrus in CA than C. gloeosporioides based on in planta experiments. Both species were commonly isolated from symptomatic tissues and were often found coinfecting the symptomatic samples but were never found associated with other known canker pathogen species of citrus within Botryosphaeriaceae and Diatrypaceae. Unlike anthracnose, which can cause twig dieback and is associated with $C$. gloeosporioides, this disease is associated with two species of Colletotrichum and is not limited to twig dieback alone but is also associated with shoot dieback and in some cases, woody cankers. Taken together, this confirms $C$. karstii as a new pathogen of citrus in California causing a disease distinct from anthracnose that is caused by C. gloeosporioides.

The association of $C$. karstii with citrus twig and shoot dieback in California represents a significant finding since this is the first report of $C$. karstii as a pathogen of citrus in the United States. Anthracnose disease of citrus was mainly attributed thus far to $C$. gloeosporioides and $C$. acutatum that are considered mainly as foliar and fruit pathogens (Timmer et al. 2000). Although symptoms of anthracnose caused by $C$. gloeosporioides in citrus include twig dieback, leaf drop, and necrosis on fruits as a postharvest disease, a progression to shoot dieback and association with branch dieback and wood

Table 2. Conidial dimensions of representative Colletotrichum spp. from citrus shoot cankers in this study and comparison with previous studies

\begin{tabular}{|c|c|c|c|c|c|}
\hline \multirow[b]{2}{*}{ Species } & \multirow[b]{2}{*}{ Isolate } & \multicolumn{3}{|c|}{ Conidial size $(\mu \mathrm{m} \text { mean } \pm \mathrm{SD})^{\mathrm{a}}$} & \multirow{2}{*}{$\frac{\text { Appressoria size }(\mu \mathrm{m} \text { mean } \pm \text { SD })^{b}}{\text { SNA }}$} \\
\hline & & PDA $^{\mathbf{c}}$ & SNA & $\mathbf{O A}$ & \\
\hline Colletotrichum karstii & UCR3550 & $15.3 \pm 1.1 \times 5.0 \pm 0.3$ & $16.1 \pm 0.8 \times 5.2 \pm 0.2$ & $14.8 \pm 0.8 \times 5.2 \pm 0.2$ & \\
\hline C. karstii & UCR3552 & $14.3 \pm 0.8 \times 5.2 \pm 0.4$ & $14.0 \pm 1.3 \times 5.6 \pm 0.5$ & $12.4 \pm 0.8 \times 5.8 \pm 0.4$ & $8.0 \pm 1.6 \times 6.1 \pm 1.1$ \\
\hline C. karstii & UCR3553 & $13.6 \pm 0.8 \times 5.9 \pm 0.3$ & $13.6 \pm 1.2 \times 5.6 \pm 0.5$ & $14.0 \pm 0.6 \times 5.8 \pm 0.4$ & $8.0 \pm 1.6 \times 6.1 \pm 1.1$ \\
\hline C. karstii & UCR1717 & $13.5 \pm 1.1 \times 7.5 \pm 0.3$ & $\ldots$ & $\ldots$ & $\ldots$ \\
\hline C. karstii & UCR1763 & $13.5 \pm 1.1 \times 7.5 \pm 0.3$ & $\ldots$ & $\ldots$ & $\ldots$ \\
\hline C. gloeosporioides & UCR2410 & $13.5 \pm 1.1 \times 7.5 \pm 0.3$ & $16.3 \pm 0.6 \times 5.2 \pm 0.4$ & $15.6 \pm 0.7 \times 5.4 \pm 0.3$ & $11.9 \pm 2.4 \times 6.5 \pm 1.0$ \\
\hline C. gloeosporioides & UCR2411 & $13.5 \pm 1.1 \times 7.5 \pm 0.3$ & $16.2 \pm 1.2 \times 5.2 \pm 0.5$ & $15.3 \pm 0.7 \times 5.4 \pm 0.4$ & $10.5 \pm 1.9 \times 7.0 \pm 1.3$ \\
\hline C. gloeosporioides & UCR2412 & $13.5 \pm 1.1 \times 7.5 \pm 0.3$ & $15.8 \pm 0.9 \times 5.2 \pm 0.4$ & $15.1 \pm 0.3 \times 5.4 \pm 0.3$ & $11.0 \pm 2.2 \times 6.7 \pm 1.3$ \\
\hline C. gloeosporioides & UCR2552 & $13.5 \pm 1.1 \times 7.5 \pm 0.3$ & $15.5 \pm 1.4 \times 5.2 \pm 0.4$ & $14.4 \pm 1.2 \times 5.1 \pm 0.5$ & $11.7 \pm 1.9 \times 7.3 \pm 1.6$ \\
\hline C. gloeosporioides & UCR2564 & $13.5 \pm 1.1 \times 7.5 \pm 0.3$ & $15.3 \pm 1.3 \times 4.6 \pm 0.5$ & $14.3 \pm 1.0 \times 4.7 \pm 0.3$ & $11.0 \pm 2.3 \times 6.8 \pm 1.5$ \\
\hline C. gloeosporioides & UCR2569 & $13.5 \pm 1.1 \times 7.5 \pm 0.3$ & $15.4 \pm 0.8 \times 4.7 \pm 0.4$ & $15.2 \pm 1.9 \times 5.1 \pm 0.4$ & $11.6 \pm 2.8 \times 7.2 \pm 1.3$ \\
\hline C. gloeosporioides & UCR3551 & $13.5 \pm 1.1 \times 7.5 \pm 0.3$ & $15.5 \pm 0.7 \times 4.6 \pm 0.3$ & $14.3 \pm 0.9 \times 4.9 \pm 0.4$ & $\ldots$ \\
\hline
\end{tabular}

${ }^{a}$ Conidial means and standard deviation (SD) were determined from 30 conidia for each isolate.

${ }^{\mathrm{b}}$ Appressoria means and standard deviation (SD) were determined from 15 appressoria for each isolate.

${ }^{\mathrm{c}} \mathrm{PDA}=$ Potato dextrose agar; SNA = synthetic nutrient-poor agar; $\mathrm{OA}=$ oatmeal agar. 
cankers has not been observed (Timmer et al. 2000; J. E. Adaskaveg, personal communication). However, shoot blight is a symptom of Key lime anthracnose caused by $C$. acutatum, but this disease affects only Key lime (Peres et al. 2008). Several studies have shown the ability of Colletotrichum to cause shoot dieback in olive, red stinkwood, poplars, camellia, coprosma, almond, apple, and persimmon (Adaskaveg and Förster 2000; Forbes and Pearson 1987; Marks et al. 1965; Moral et al. 2009; Mwanza et al. 1999; Sun et al. 2014; Roberts 1915; Zhang 2008).

Recently, Ramos et al. (2016) determined C. karstii, in addition to C. gloeosporioides, to be commonly associated with twig dieback of lemon in Portugal and found both species capable of causing dieback and branch necrosis of sweet orange and mandarin in the field. Although results from pathogenicity tests in our study did not reproduce
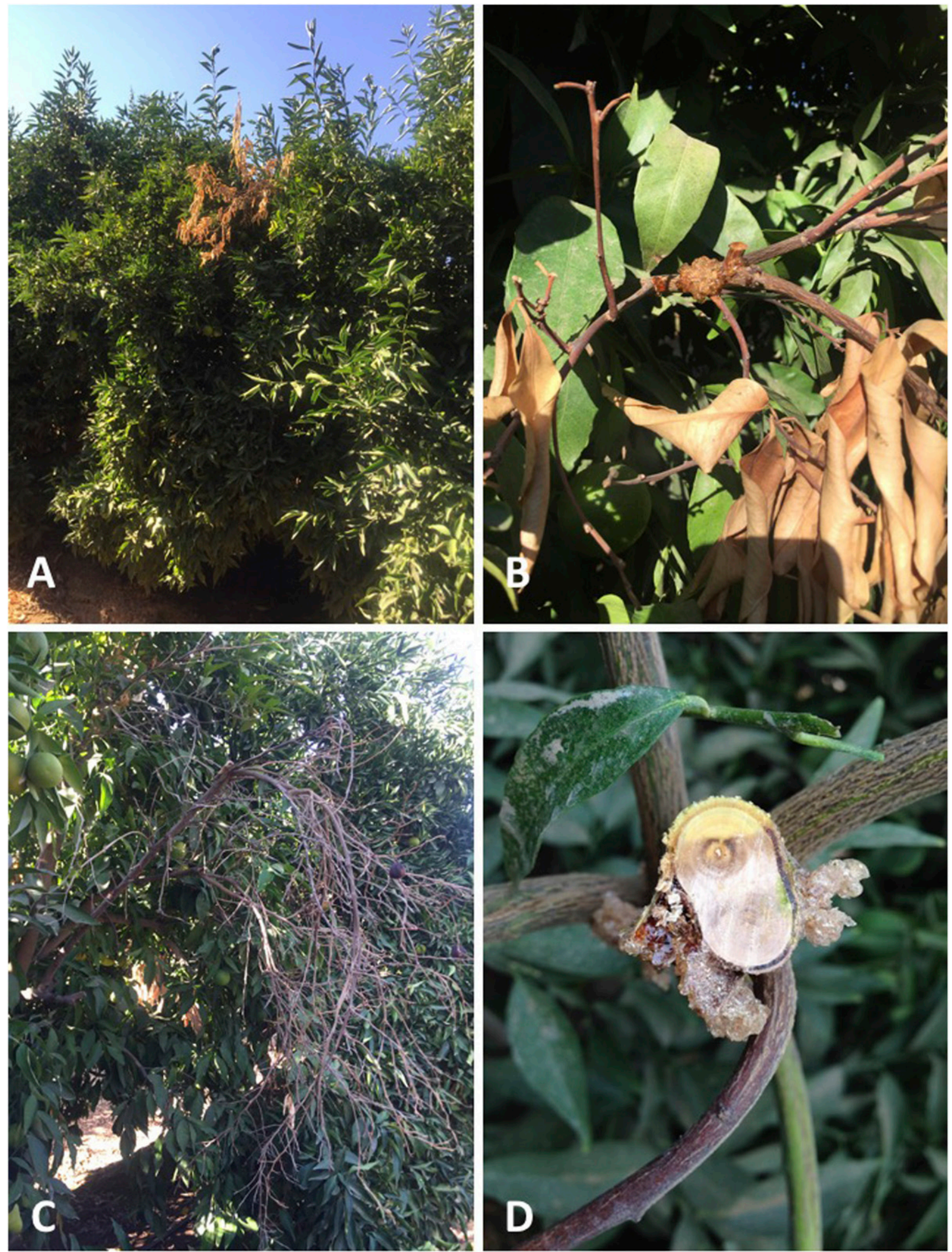

Fig. 1. Symptoms of Colletotrichum dieback. A, Shoot dieback symptoms on clementine. B, Gumming symptoms on an infested shoot. C, Branch dieback symptoms on clementine. $\mathrm{D}$, Wood discoloration and canker on the wood. 
the branch dieback observed in commercial citrus orchards, the ability of both Colletotrichum spp. to cause internal vascular necrosis of mandarin supports the findings of Ramos et al. and confirms the status of $C$. karstii as an emerging pathogen of citrus. At present, it is unclear if $C$. karstii can cause leaf anthracnose in California citrus although it has been isolated from leaf lesions and confirmed to infect leaves of several citrus varieties in other regions (Peng et al. 2012; Ramos et al. 2016). C. karstii has been reported also as causing preharvest anthracnose on sweet orange (Aiello et al. 2015), but this symptom was not observed in our study.

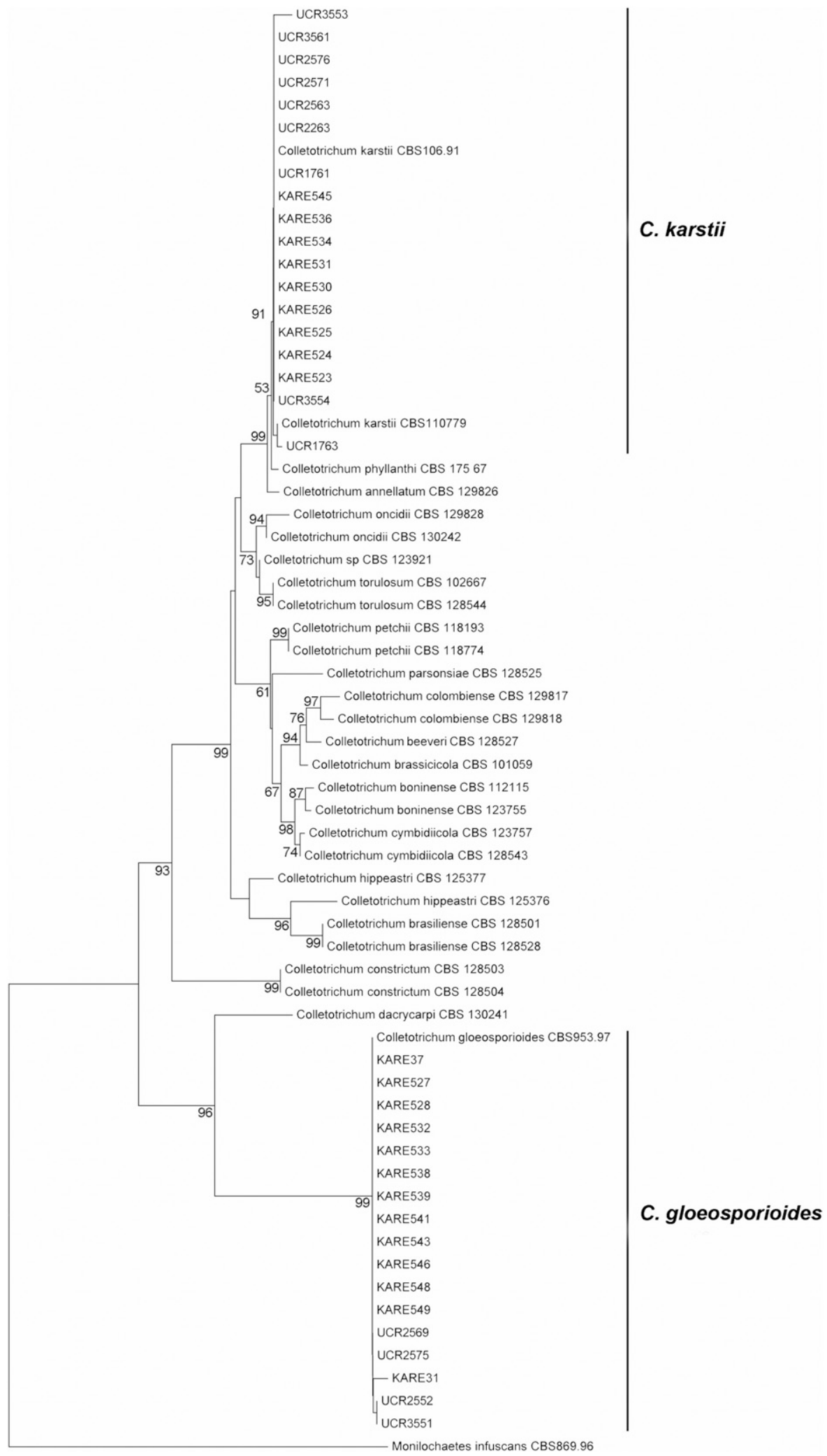

Fig. 2. One of the most parsimonious unrooted trees based on internal transcribed spacer 1, $5.8 \mathrm{~S}$ ribosomal DNA, ITS2 (ITS); 200 bp intron of the glyceraldehyde-3-phosphate dehydrogenase gene (GAPDH); and partial $\beta$-tubulin gene region (TUB2) sequences for isolates of species of the Colletotrichum boninense species complex inferred from maximum parsimony analysis. Numbers on branches are bootstrap values from 1,000 bootstrap replicates. 
During this study, C. karstii was isolated from citrus wood canker samples that resembled wood canker symptoms typical of those caused by Botryosphaeria and its allied members (Adesemoye et al. 2014). Isolations from the wood canker samples collected during this study yielded only $C$. karstii and $C$. gloeosporioides, suggesting these species may act as canker pathogens or as secondary invaders, or possibly saprobes colonizing tissues previously killed by branch canker pathogens like Botryosphaeria spp. The latter seems unlikely as no Botryosphaeria spp. or other canker pathogens typically associated with citrus were recovered from those samples. Phytotoxins may also contribute to the symptoms observed as toxins produced by $C$. acutatum have been shown to cause wilting and branch dieback in olive (Moral et al. 2009). It is unknown if the Colletotrichum spp. presented in this study produce phytotoxins that directly contribute to the cankering and dieback observed. In hosts such as apple and persimmon, anthracnose symptoms can include both

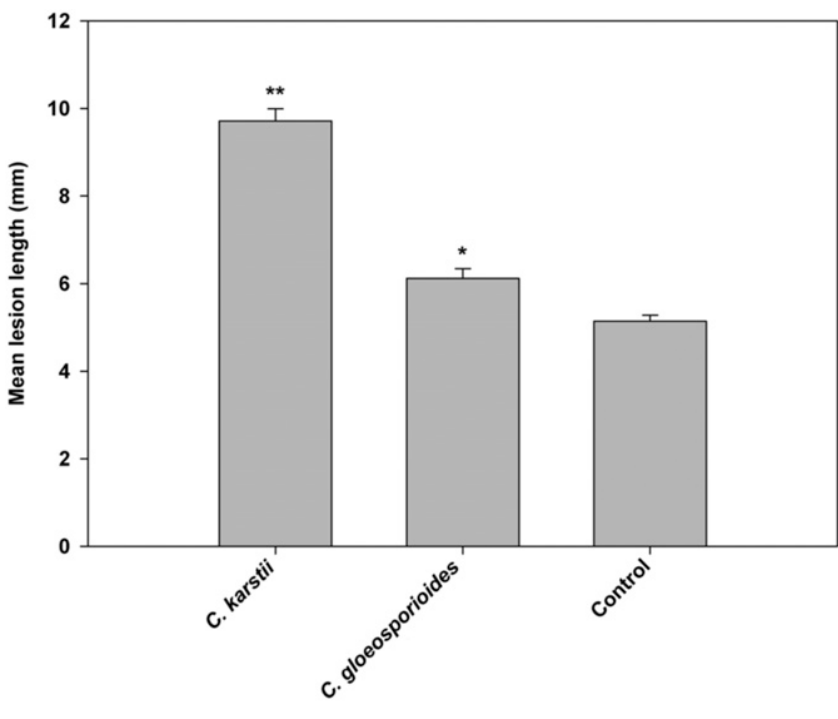

Fungal Isolates

Fig. 3. Pathogenicity of Colletotrichum spp. on ' $4 \mathrm{~B}$ ' clementine after 10 days. Vertical lines represent standard error of the mean. Asterisks $\left(^{*}\right)$ denote the following significance: ${ }^{*}=P<0.05$ and ${ }^{* *}=P<0.01$.

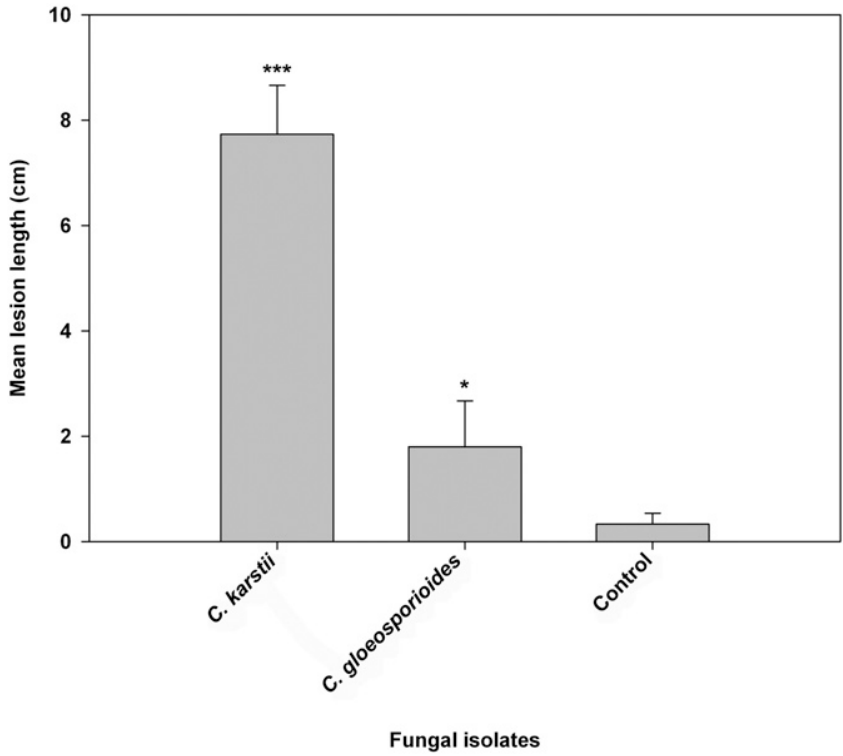

Fig. 4. Pathogenicity of Colletotrichum spp. on '4B' clementine after 15 months. Vertical lines represent standard error of the mean. Asterisks $\left(^{*}\right)$ denote the following significance: ${ }^{*}=P<0.05$ and ${ }^{* * *}=P<0.001$. shoot dieback and wood cankers (Roberts 1915; Zhang 2008). In these cases, the dieback observed in twigs and shoots can also progress into woody branches if the infection is severe. Pathogenicity results from this study confirmed $C$. karstii as a pathogen of citrus and suggest that this fungus may also be responsible for causing typical branch canker symptoms (gumming, depressed bark with the presence of fruiting bodies, and vascular necrosis) observed in lath house inoculated plants. Nevertheless, long-term field pathogenicity studies will be necessary to determine the severity of vascular cankers caused by these fungi.

C. karstii is distributed worldwide throughout Africa, Asia, North and South America, Europe, and Oceania and is associated with a number of plant species including agricultural commodities such as apple (Velho et al. 2014), avocado (Velázquez-del Valle et al. 2016), citrus (Guarnaccia et al. 2017; Huang et al. 2013; Peng et al. 2012; Ramos et al. 2016), mango (Lima et al. 2013), olive (Schena et al. 2014), and pistachio (Lichtemberg et al. 2017). It is considered the most common and diverse 'species' in the C. boninense complex (Damm et al. 2012). However, C. karstii has only been reported from citrus in China, Italy, Malta, New Zealand, Portugal, Spain and South Africa (Aiello et al. 2015; Huang et al. 2013; Peng et al. 2012; Ramos et al. 2016). C. karstii is a plurivorous

A

Kern Co.
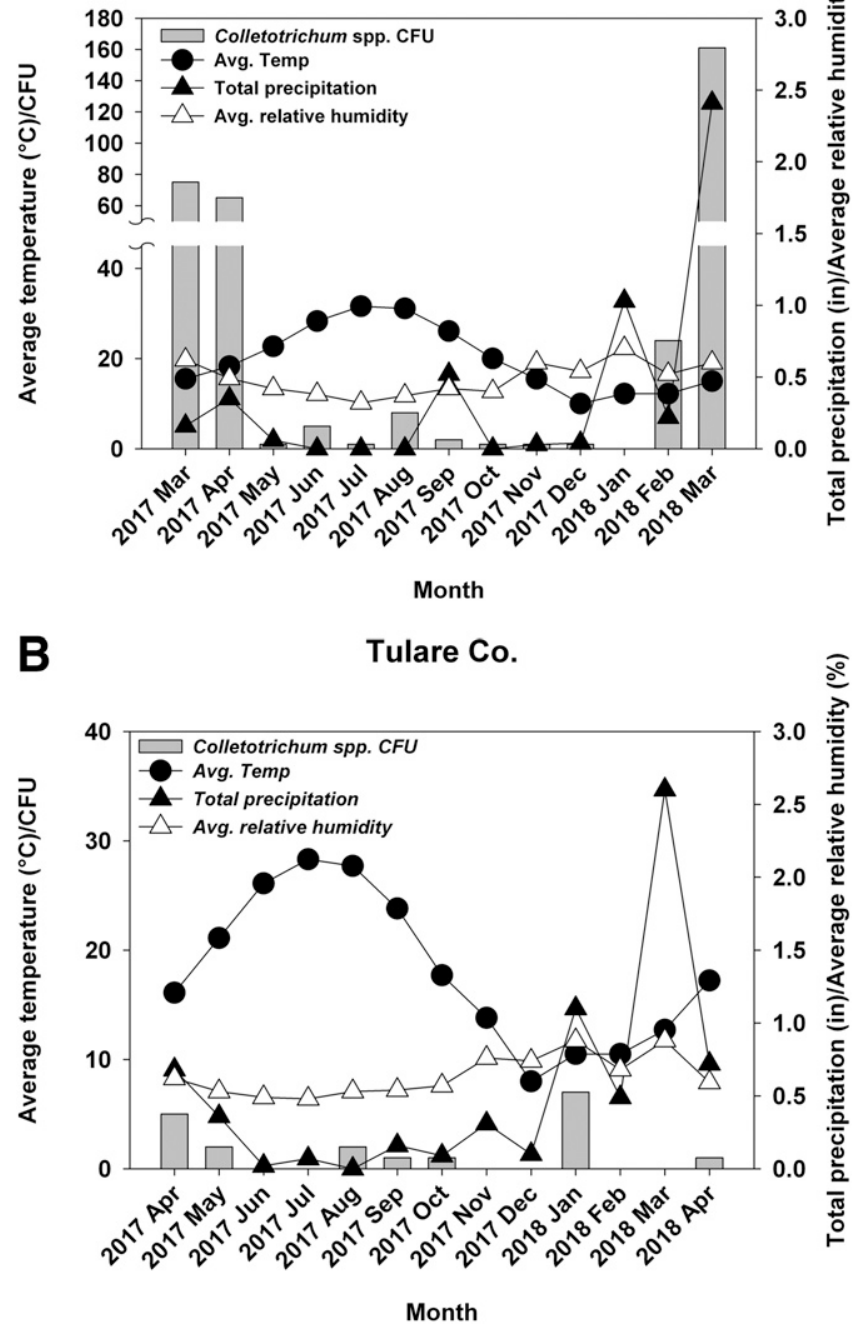

Fig. 5. Monthly spore trap counts with temperature $\left({ }^{\circ} \mathrm{C}\right)$, precipitation $(\mathrm{mm})$, and relative humidity (\%) for $\mathbf{A}$, Kern and $\mathbf{B}$, Tulare counties. Vertical bars represent total colony forming units (CFU) counted from each citrus orchard by month. Lines represent average monthly temperature $\left({ }^{\circ} \mathrm{C}\right)$ and relative humidity $(\%)$ and total monthly precipitation $(\mathrm{mm})$ 
pathogen and within citrus specifically, it does not appear to be variety specific since it was found on several varieties of citrus during this study as well as other studies (Guarnaccia et al. 2017; Huang et al. 2013; Peng et al. 2012; Ramos et al. 2016). Damm et al. (2012) reported high sequence variability within strains of $C$. karstii that were sequenced from various hosts throughout the world; however, in this study, strains collected from various citrus species and locations throughout California showed very little genetic variability within either species. It is unknown at this time if this lack of genetic variability could be attributed to clonal population structure of both species on citrus in California. Additional studies utilizing additional markers such as microsatellites, AFLP, or RAD-sequencing would help to resolve this aspect of their biology/epidemiology.

Although little is known regarding the epidemiology of $C$. karstii on citrus, several environmental factors are likely important for the dissemination and progression of this disease. Relative humidity and precipitation in citrus orchards in California play an important role in the epidemiology of Colletotrichum infection whereby conidia dispersed by rain and humidity are conducive to pathogen spread (Dodd et al. 1989; Hunter and Buddenhagen 1972; Jeffries et al. 1990). Our spore trap study showed that spore trapping of Colletotrichum species occurred most frequently during the months with the highest precipitation (Fig. 5), but Colletotrichum spp. were not always correlated with rainfall. Similar results were found with other spore trap studies in California (Eskalen and Gubler 2001; Eskalen et al. 2013; Úrbez-Torres et al. 2010). Wounding is also known to predispose plants to infection by Colletotrichum (Lubbe et al. 2006; Muimba-Kankolongo and Bergstrom 1992; Shaw 1995) and typical agricultural practices and the environment in CA citrus groves (pruning, shearing, wind/sand damage) give both of these species the opportunity to colonize citrus trees. During this study, symptoms were observed during the late spring and summer months, with no new symptoms being observed into fall, winter, and early spring. This suggests that young, tender tissues developing in the late spring are likely necessary for initial pathogen colonization.

The findings of this study have determined $C$. karstii to be a new pathogen of citrus in California associated with a disease which is distinct from citrus anthracnose caused by $C$. gloeosporioides. Additionally, C. karstii is a more aggressive pathogen than C. gloeosporioides and more remains to be understood regarding the disease cycle of this pathogen, which raises concerns for the management of this new pathosystem. Currently no strategies exist for the management of this emerging disease in citrus. Adherence to cultural practices recommended for the management of canker and dieback pathogens should be followed. These practices include maintaining trees in good condition through appropriate irrigation regimens and proper fertilization, removal of infested branches and pruning debris during dry periods followed by immediate disposal of infested material, and sanitizing pruning equipment. Chemical management using fungicides is being investigated and these methods may become part of an integrated pest management strategy for Colletotrichum diseases of citrus in California.

\section{Acknowledgments}

Plants used for pathogenicity tests were kindly donated by Wonderful Citrus. We thank D. Trannam, R. Yuan, K. Sugino, Q. Douhan, and our cooperating citrus growers for assistance in the lab and field. Thanks to Raul Garcia, Gless Ranch, and Robert Walther, Entomological Services, Inc., for donating their time and ranches for sample collection. We also thank the anonymous reviewers for their constructive comments.

\section{Literature Cited}

Adaskaveg, J., and Förster, H. 2000. Occurrence and management of anthracnose epidemics caused by Colletotrichum species on fruit tree crops in California. Pages 317-336 in: Colletotrichum: Host Specificity, Pathology and Hostpathogen Interaction. D. Prusky, S. Freeman, and M. B. Dickman, eds. The American Phytopathological Society Press, St. Paul, MN.

Adesemoye, A. O., Mayorquin, J. S., Wang, D. H., Twizeyimana, M., Lynch, S.

C., and Eskalen, A. 2014. Identification of species of Botryosphaeriaceae causing Bot Gummosis in citrus in California. Plant Dis. 98:55-61.

Agrios, G. N. 2005. Plant Pathology. Academic Press, Burlington, MA
Aiello, D., Carrieri, R., Guarnaccia, V., Vitale, A., Lahoz, E., and Polizzi, G. 2015. Characterization and pathogenicity of Colletotrichum gloeosporioides and C. karstii causing preharvest disease on Citrus sinensis in Italy. J. Phytopathol. 163:168-177.

Cannon, P. F., Damm, U., Johnston, P. R., and Weir, B. S. 2012. Colletotrichum current status and future directions. Stud. Mycol. 73:181-213.

Cenis, J. L. 1992. Rapid extraction of fungal DNA for PCR amplification. Nucleic Acids Res. 20:2380.

Crous, P. W., Denman, S., Taylor, J. E., Swart, L., Bezuidenhout, C. M., Hoffman, L., Palm, M. E., and Groenewald, J. Z. 2013. Cultivation and diseases of Proteaceae: Leucadendron, Leucospermum and Protea. 2nd edn. CBS Biodiversity Series no. 13. CBSKNAW Fungal Biodiversity Centre, Utrecht, The Netherlands.

Damm, U., Cannon, P., Woudenberg, J., Johnston, P., Weir, B., Tan, Y., Shivas, R., and Crous, P. 2012. The Colletotrichum boninense species complex. Stud. Mycol. 73:1-36.

Dean, R., Van Kan, J. A. L., Pretorious, Z. A., Hammond-Kosack, K. E., Di Pietro, A., Spanu, P. D., Rudd, J. J., Dickman, M., Kahmann, R., Ellis, J., and Foster, G. D. 2012. The Top 10 fungal pathogens in molecular plant pathology. Mol. Plant Pathol. 13:414-430.

Dodd, J. C., Jeffries, P., and Jeger, M. J. 1989. Management strategies to control latent infection in tropical fruit. Asp. Appl. Biol. 20:49-56.

Eskalen, A., Faber, B., and Bianchi, M. 2013. Spore trapping and pathogenicity of fungi in the Botryosphaeriaceae and Diaporthaceae associated with avocado branch canker in California. Plant Dis. 97:329-332.

Eskalen, A., and Gubler, W. 2001. Association of spores of Phaeomoniella chlamydospora, Phaeoacremonium inflatipes, and Pm. aleophilum with grapevine cordons in California. Phytopathol. Mediterr. 40:429-432.

Forbes, S. K., and Pearson, M. N. 1987. Fungal pathogens associated with dieback, stem canker and anthracnose of Coprosma spp. in the Auckland area New Zealand. N. Z. J. Bot. 25:275-280.

Guarnaccia, V., Groenewald, J. Z., Polizzi, G., and Crous, P. W. 2017. High species diversity in Colletotrichum associated with citrus diseases in Europe. Persoonia 39:32-50.

Guerber, J. C., Liu, B., Correll, J. C., and Johnston, P. R. 2003. Characterization of diversity in Colletotrichum acutatum sensu lato by sequence analysis of two gene introns, mtDNA and intron RFLPs, and mating compatibility. Mycologia 95:872-895.

Harris, J. L. 1986. Modified method for fungal slide culture. J. Clin. Microbiol. 24: 460-461.

Huang, F., Chen, G. Q., Hou, X., Fu, Y. S., Cai, L., Hyde, K. D., and Li, H. Y 2013. Colletotrichum species associated with cultivated citrus in China Fungal Divers. 61:61-74.

Hunter, J. E., and Buddenhagen, I. W. 1972. Incidence, epidemiology and control of fruit diseases of papaya in Hawaii. Trop. Agr. Trinidad 49: 61-71.

Hyde, K. D., Cai, L., McKenzie, E. H. C., Yang, Y. L., Zhang, J. Z., and Prihastuti, H. 2009. Colletotrichum: a catalogue of confusion. Fungal Divers. 39:117-124

Ismail, A. M., Cirvilleri, G., Yaseen, T., Epifani, F., Perrone, G., and Polizzi, G. 2015. Characterization of Colletotrichum species causing anthracnose disease of mango in Italy. J. Plant Pathol. 97:167-171.

Jadrane, I., Kornievsky, M., Desjardin, D. E., He, Z. H., Cai, L., and Hyde, K 2012. First report of flower anthracnose caused by Colletotrichum karstii in white Phalaenopsis orchids in the United States. Plant Dis. 96:1227-1227.

Jeffries, P., Dodd, J. C., Jeger, M. J., and Plumbley, R. A. 1990. The biology and control of Colletotrichum species on tropical fruit crops. Plant Pathol. 39: 343-366.

Kankolongo, A., and Bergstrom, G. C. 1992. Wound predisposition of maize to anthracnose stalk rot as affected by internode position and inoculum concentration of Colletotrichum graminicola. Plant Dis. 76:188-195.

Klotz, J. 1961. Color Handbook of Citrus Diseases. University of California, Riverside, CA.

Lenne, J. M. 2002. Some major plant diseases. Pages 4-18 in: Plant Pathologist's Pocketbook, 3rd Ed., J. M. Waller, J. M. Lenne, and S. J. Waller, eds. CABI, Wallingford, UK.

Lichtemberg, P. S. F., Moral, J., Morgan, D. P., Felts, D. G., Sanders, R. D., and Michailides, T. J. 2017. First report of anthracnose caused by Colletotrichum fioriniae and $C$. karstii in California pistachio orchards. Plant Dis. 101:1320.

Lima, N. B., Marques, M., Michereff, S., Morais, M., Jr., Barbosa, M. A., and Camara, M. P. S. 2013. First report of mango anthracnose caused by Colletotrichum karstii in Brazil. Plant Dis. 97:1248.

Lubbe, C. M., Denman, S., Lamprecht, S. C., and Crous, P. W. 2006. Pathogenicity of Colletotrichum species to Protea cultivars. Australas. Plant Pathol. 35:37-41.

Marks, G. C., Berbee, J. G., and Riker, A. J. 1965. Colletotrichum shoot blight of poplars. For. Sci. 11:204-215.

Moral, J., de Oliveira, R., and Trapero, A. 2009. Elucidation of the disease cycle of olive anthracnose caused by Colletotrichum acutatum. Phytopathology 99:548-556.

Mwanza, E. J. M., Waithaka, S. K., Mibey, R. K., Kariuki, G., and Simons, S. A 1999. First report of Colletotrichum gloeosporioides as a foliar and die-back pathogen of Prunus africana in Kenya. Plant Dis. 83:79. 
Peng, L., Yang, Y., Hyde, K. D., Bahkali, A. H., and Liu, Z. 2012. Colletotrichum species on citrus leaves in Guizhou and Yunnan Provinces, China. Cryptogam., Mycol. 33:267-283.

Peres, N. A., MacKenzie, S. J., Peever, T. L., and Timmer, L. W. 2008. Postbloom fruit drop of citrus and key lime anthracnose are caused by distinct phylogenetic lineages of Colletotrichum acutatum. Phytopathology 98:345-352.

Ramos, A. P., Talhinhas, P., Sreenivasaprasad, S., and Oliveira, H. 2016. Characterization of Colletotrichum gloeosporioides, as the main causal agent of citrus anthracnose, and $C$. karstii as species preferentially associated with lemon twig dieback in Portugal. Phytoparasitica 44:549-561.

Roberts, J. W. 1915. Sources of the early infections of apple bitter-rot. J. Agric. Res. 4:59-64.

Schena, L., Mosca, S., Cacciola, S. O., Faedda, R., Sanzani, S. M., Agosteo, G. E., Sergeeva, V., and Magnano di San Lio, G. 2014. Species of the Colletotrichum gloeosporioides and $C$. boninense complexes associated with olive anthracnose. Plant Pathol. 63:437-446.

Shaw, D. E. 1995. Infection by Colletotrichum gloeosporioides through lesions of Puccinia paullula f. sp. monsterae on Monstera deliciosa. Mycologist 9: 131-134.

Silva-Rojas, H. V., and Ávila-Quezada, G. D. 2011. Identification of Colletotrichum boninense: a novel causal agent of anthracnose in avocado. Plant Pathol. 60:899-908.

Sun, S., Wang, J., Zhao, H., Zhang, M., Shu, C., Wang, X., and Zhou, E. 2014. First report of dieback of Camellia azalea caused by Glomerella cingulata $f$. sp. camelliae in Guangdong, China. Plant Dis. 98:1583.

Tamura, K., Stecher, G., Peterson, D., Filipski, A., and Kumar, S. 2013. MEGA6: Molecular Evolutionary Genetics Analysis Version 6.0. Mol. Biol. Evol. 30: 2725-2729.
Thompson, J. D., Gibson, T. J., Plewniak, F., Jeanmougin, F., and Higgins, D. G. 1997. The CLUSTAL_X windows interface: flexible strategies for multiple sequence alignment aided by quality analysis tools. Nucleic Acids Res. 25:4876-4882.

Timmer, L. W., Garnsey, S. M., and Graham, J. H., eds. 2000. Compendium of Citrus Diseases, 2nd Ed. American Phytopathological Society, St. Paul, MN.

United States Department of Agriculture-National Agricultural Statistics Service. 2018. Citrus Fruits: 2018 Summary, September 2018. USDA-NASS. https:// www.nass.usda.gov/Publications/Todays_Reports/reports/cfrt0818.pdf

Úrbez -Torres, J. R., Battany, M., Bettiga, L. J., and Gubler, W. D. 2010 Botryosphaeriaceae species spore-trapping studies in California vineyards. Plant Dis. 94:717-724.

Velázquez-del Valle, M. G., Campos-Martinez, A., Flores-Moctezuma, H. E., Suarez-Rodriguez, R., Ramirez-Trujillo, J. A., and Hernandez-Lauzardo, A. N. 2016. First report of avocado anthracnose caused by Colletotrichum karstii in Mexico. Plant Dis. 100:534.

Velho, A. C., Stadnik, M. J., Casanova, L., Mondino, P., and Alaniz, S. 2014. First report of Colletotrichum karstii causing glomerella leaf spot on apple in Santa Catarina State, Brazil. Plant Dis. 98:157.

Wang, J., Ai, C. X., Yu, X. M., An, M., Sun, S., and Gao, R. 2016. First report of Colletotrichum karstii causing anthracnose on persimmon leaves in China. Plant Dis. 100:532-532.

Weir, B. S., Johnston, P. R., and Damm, U. 2012. The Colletotrichum gloeosporioides species complex. Stud. Mycol. 73:115-180.

White, T. J., Bruns, T., Lee, S., and Taylor, J. 1990. Pages 315-322 in: PCR Protocols: A Guide to Methods and Applications. Academic Press, San Diego, CA.

Zhang, J.-Z. 2008. Anthracnose of Persimmon Caused by Colletotrichum gloeosporioides in China. Asian Australas. J. Plant Sci. Biotechnol. 2:50-54. 